\title{
Movimiento estudiantil en Chile 2011: Causas y características
}

\author{
Enrique Cañas Kirby ${ }^{1}$ \\ Recibido: 20 de agosto de 2015 - Aceptado: 15 de abril de 2016
}

\begin{abstract}
Resumen
Los movimientos de protesta estudiantil en la historia de Chile del siglo XX configuran un tipo de acción colectiva que tienen como patrón común un grado específico de influencia y agregación de otros actores sociales en momentos críticos del proceso político. Este artículo pretende averiguar el impacto que tuvo en Chile el movimiento 2011 sobre las estructuras formales de poder en el sistema político. Se han levantado teorías sociales acerca de este fenómeno que refieren a formas de participación y representación política que tienden a distanciarse de los asuntos cívicos. Chile no es un caso aislado en este respecto. Para saberlo, es necesario conocer las coordenadas sobre las cuales transcurrió la cuestión social en 2011, sus precedentes y proyecciones.
\end{abstract}

Palabras clave: Movimientos sociales, representación política, teoría política, historia de Chile.

\section{Student movement in Chile 2011: Causes and characteristics}

\begin{abstract}
The student protest movements in the history of Chile in the Twentieth Century formed a kind of collective action having in common a specific degree of influence and aggregation of other social actors in critical moments of the political process. This article aims to determine the impact of the 2011 movement in Chile on the formal structures of power in the political system. Social theories have been raised about this phenomenon referring to forms of political participation and representation that tend to get apart from civic affairs. Chile is not an isolated case in this regard. To find out, it is necessary to know the coordinates on which the social question occurred in 2011, its precedents and projections.
\end{abstract}

Keywords: Social movements, political representation, political theory, history of Chile. 


\section{Movimento estudantil no Chile 2011: Causas e características}

\section{Resumo}

Os movimentos de protesto estudantis na história do Chile século XX configuram-se como uma espécie de ação coletiva que tem como padrão em comum um determinado grau de influência e agregação de outros atores sociais em momentos críticos do processo político. Este artigo pretende indagar no impacto do movimento de 2011 no Chile, sobre as estruturas formais de poder no sistema político. Têm sido levantadas teorias sociais sobre este fenómeno referindo-se a formas de participação e representação política que tendem a distanciar-se dos assuntos cívicos. Chile não é um caso isolado a este respeito. Para conhecê-lo, é preciso saber as coordenadas sobre as quais transcorreu a questão social em 2011, seus antecedentes e projeções.

Palavras-chave: Movimentos sociais, representação política, teoria política, história do Chile.

Tratar la problemática de los movimientos sociales y, específicamente, los movimientos estudiantiles, implica entrar en un campo de análisis denso y complejo por la heterogeneidad de variables que deben ser usadas para su estudio explicativo y por la pluralidad de significados y despliegues teóricos que acompañan la observación de tales procesos (Aguilar Solé, 2001; Paredes, 2011; Touraine, 1998; Traugott, 2002; Macadam, 1999). En este trabajo nos centramos en el movimiento estudiantil chileno del siglo XXI, destacando los momentos 2006 y 2011, correspondientes a gobiernos de tendencias antagónicas, en que se homologa una actitud política de bajo poder resolutivo en cuanto a dar respuesta al anhelo de materializar en Chile una educación de calidad y sin fines de lucro. Estudiar este problema exige tener en cuenta un abanico de objetivos, circunstancias, resultados y un conjunto diferenciado de actores que se sumaron al movimiento estudiantil y que actuaron para reclamar condiciones de vida más justas.

Uno de los puntos importantes que trata de poner en discusión este artículo es la forma en que se configura una acción colectiva a partir de la columna vertebral reflejada en el movimiento estudiantil a través de su expresión en la calle.

Desde que se produjera la llamada "revolución pingüina" (Falabella, 2008) de estudiantes secundarios en 2006, el fenómeno del movimiento estudiantil tuvo un impacto progresivo de agregación de otros actores que se incorporaron activamente a las circunstancias movimentales masivas del estudiantado, aprovechando esa coyuntura no sólo para apoyar a los jóvenes, sino para reclamar sus propias demandas sectoriales frente a las deficiencias del Estado para gestionar políticas sectoriales de impacto efectivo, como el sueldo mínimo, la reforma tributaria, la calidad de la salud, y otros elementos 
como la reforma a la Constitución Política de 1980, que carece de legitimidad de origen, representa a un solo sector de la sociedad e impone fuertes trabas para su modificación y para legislar sobre temas importantes.

Los estudiantes rechazaron un tipo de sistema educacional con evidentes inequidades entre segmentos sociales, con amplias atribuciones del sector privado respecto al Estado y en donde el mercado adquiere una función que incita a la competencia entre educación estatal-municipalizada y la educación privada. Queda degradada de esa forma la equidad educacional en todos los tramos, con efectos viciados en el ámbito de la medición de conocimientos aplicada a un mundo dividido en el acceso a esos conocimientos. Este proceso alentó con más fuerza en la sociedad chilena el conocimiento de grandes fisuras sociales.

La historia de Chile ha estado enlazada al movimiento estudiantil por más de un siglo de lucha. A principios de 1900, se comienzan a agudizar las desigualdades sociales en el país y empiezan a surgir distintos movimientos sociales. En el campo de la educación también se percibe la necesidad de cambiar las deficiencias de un sistema retrógrado, carente de sintonía con los cambios que se vienen con el inicio del siglo XX. De esta manera, la juventud estudiantil chilena realiza su primera irrupción transgresora en 1906, lo que fue comentado como un escándalo por las elites criollas. Los jóvenes abuchearon a la oligarquía de gala reunida en el Teatro Municipal de Santiago donde se realizaba un acto para condecorar a los jóvenes que habían auxiliado a los damnificados del terremoto de Valparaíso (Meller, 1996; Thielemann, 2012).

La primera gran reforma educacional chilena comenzó a difundirse en 1928, apoyada por varias agrupaciones de profesores. Entre sus objetivos estaba democratizar la educación, constituir el Estado docente, modernizar las técnicas pedagógicas y adecuar el modelo educacional a las necesidades del país. Establecía como principio básico a la educación como función propia del Estado y, como tal, sería gratuita. Intenta con ello favorecer el desarrollo integral del individuo, de acuerdo con las vocaciones que manifestara. La reforma educacional fracasó en desarrollar todos estos puntos, fue calificada de izquierdista y quedó estancada al poco tiempo, pero la idea de introducir cambios en el sistema educacional siguió presente en las décadas siguientes.

En los años 30, con el surgimiento del Frente Popular, se produce un gran movimiento cultural y artístico, que tiene su base en la Universidad de Chile (Moulian, 2006; Cruz Coke, 1984). El Teatro Experimental, la Orquesta Sinfónica, el Ballet, en fin, la extensión cultural, son impulsados por los estudiantes y por el rector Juvenal Hernández, que habría sido nombrado tras varias jornadas de presión estudiantil (Moraga Valle, 2007; Edwards Vives, 1928; Correa, 2001). El Frente Popular fue una coalición político-electoral de partidos políticos originada el 6 de mayo de 1936. Se organizó sobre la 
base del Partido Radical, Partido Comunista de Chile, Partido Democrático, Partido Socialista de Chile y el Partido Radical Socialista. A partir de 1938 llevó a la Presidencia a Pedro Aguirre Cerda.

En los finales de los años cuarenta y la década siguiente los estudiantes empiezan a manifestarse demandando menos autoritarismo y verticalismo dentro de la universidad y sus aulas. Se comenzaron a exigir lugares de discusión y mayor tolerancia a las nuevas ideas. De esta manera, el movimiento estudiantil mostraba su vertiente anti-autoritaria y libertaria. En estas décadas se viven dos revueltas sociales importantes: La revolución de las chauchas y la batalla de Santiago. Ambos acontecimientos con gran participación estudiantil (Vitale, 1998). El blanco principal de las protestas fue la locomoción colectiva, que el día 12 de agosto había alzado sus tarifas, provocando la ira de los santiaguinos.

Más adelante las universidades serán cuna de la generación estudiantil de mayor protagonismo en la historia nacional, así ocurrió en 1968. Esta generación surge con la incorporación de importantes sectores medios y bajos de la sociedad, los cuales por primera vez tenían la oportunidad de ingresar a la educación superior. Su idea de vida era transformar drásticamente la sociedad y encontraron en la universidad un espacio para desenvolverse. La generación estudiantil del 68 (Salazar, 1986; Millas, 1983; Boeninger, 1968) no buscó como escenario de su proyecto histórico el aparato político del Estado, sino el territorio social y popular: la calle, la fábrica, el fundo, la plaza. Democratizarla hacia afuera para permitir el ingreso masivo de las clases populares a la universidad. Y democratizarla hacia adentro para transformar sus estructuras rígidas en plataformas de decisión democrática entre los distintos estamentos: estudiantes, profesores y trabajadores, lo que llamamos triestamentalidad. Los estatutos de la Universidad de Concepción se reformaron y se estableció que los organismos superiores serían el claustro pleno y el consejo superior (Casals Araya, 2010).

Por esos años la presión social logró que se declarara la autonomía universitaria, lo cual, en palabras simples quería decir que no podía ingresar ningún tipo de fuerzas armadas al terreno universitario (La Reforma Universitaria y el movimiento estudiantil, 1972). Los grandes cambios se potenciaron durante el periodo de la Unidad Popular (Allende, 1971; Mancilla y De la Cruz, 2008). En 1970, en un hecho inédito, el Parlamento chileno acogió, por unanimidad y sin cambiar una sola coma, la propuesta de la comunidad universitaria, en la cual se consagran, entre otros, los principios de: gratuidad, autonomía, libertad de cátedra y participación triestamental. De esta manera se comienza a consagrar la universidad pública y popular, proceso que fue interrumpido con el Golpe Militar de 1973. Luego de 1973 las universidades fueron brutalmente intervenidas, rediseñándolas con el propósito que sirvieran a los intereses de la dictadura y de los grupos económicos (La Reforma Universitaria y el movi- 
miento estudiantil, 1972). Las universidades comenzaron a transformarse en instituciones al servicio de la represión. El espíritu crítico fue extirpado para dar pie a la subordinación y la alienación a los grupos dominantes.

Sin embargo, los estudiantes no se rindieron y comenzó rápidamente el proceso de resistencia al régimen. En sus principios el movimiento estudiantil se refugió en el ámbito de las actividades culturales. Una revaloración de la cultura popular y la visión del arte como herramienta transformadora se apoderó de las universidades, las cuales eran sede de peñas, conciertos, concentraciones, reuniones y pequeñas asambleas. Las peñas y actividades culturales servían para conversar de los problemas políticos de la época y potenciaban el accionar subversivo. Posteriormente se avanzó a una etapa más explícitamente política, en donde a través de la reactivación de los centros de alumnos se logró luchar contra la Dictadura. Por ejemplo, en la Universidad de Concepción se levantó la Federación de Estudiantes en el año 1983. Por primera vez volvía a existir la FEC en época de dictadura, la cual había sido cerrada tras el golpe (Cañas Kirby, 1997).

A partir de 1990, con el término de la dictadura, las universidades entran en un proceso de democratización, sin embargo, este proceso se ve detenido por los grupos de poder que asumen la conducción de las universidades, los cuales ven en los estatutos y marcos jurídicos heredados de la dictadura una excelente herramienta que les permite, dentro de un marco legal, introducirse en los cargos y hacer uso y abuso de los recursos económicos y financieros, deteriorando fuertemente el patrimonio físico e intelectual de las universidades y con ello el desarrollo de la nación.

Bajo los gobiernos de la Concertación la educación de mercado se transformó en la ley (Margotta T., 2008). De esta manera, el escenario actual en lo que se refiere a Educación Universitaria está conformado por las 16 Universidades del Estado, las que constituyen el Consorcio de Universidades del Estado; 9 universidades públicas privadas que reciben aporte del Estado y que junto con las anteriores conforman las 25 universidades del Consejo de Rectores; y un número superior a 50 universidades privadas. El sistema ha anulado la participación triestamental y ha impuesto medidas tendientes a la privatización, las cuales han llevado al deterioro de la educación chilena, lo cual se refleja claramente en las desigualdades sociales que hoy vive el país y el fuerte movimiento social y estudiantil a partir de los primeros años del siglo XXI.

Hoy se instala una crítica (Mayol, 2012; Ortiz Letelier, 2012) asaz radical, en contra de un sistema educacional evidentemente estancado, básicamente desorganizado y dislocado, situación que se ha visto favorecida por un sistema económico que alienta la desmembración, la disociación y la exclusión al interior de la sociedad. Los estudiantes arremeten en contra del lucro liberal, 
la desigualdad en el acceso a la educación y los colosales contrastes en la calidad de la formación público-privada. Los años 2006 y 2011 constituye hitos históricos que vienen a representar el reventón de una crítica social que deja de ser episódica y puramente convencional para transformarse en procesos radicales en un inédito movimiento social protagonizado por los estudiantes y que se ha proyectado en el tiempo.

Nuestro objetivo es analizar las demandas del movimiento estudiantil chileno durante el período del año 2011 y sus antecedentes a partir de 2006. Partimos del supuesto hipotético general de que durante ese año, las movilizaciones del estudiantado secundario y universitario, reunido en sus respectivas confederaciones, provocaron la agregación espontánea de los más diferentes sectores de la sociedad, los cuales se expresaron multitudinariamente en cientos de marchas callejeras y otro tipo de expresiones, haciéndose manifiesto el descontento de la ciudadanía con los déficits sociales y el rechazo a la gestión de los poderes políticos, lo que venía a revelar el severo desprestigio del régimen democrático y la crítica profunda al modelo de desarrollo heredado de la dictadura.

El problema general que ordena nuestra investigación refiere a cuáles fueron los ejes de contenido y las estrategias políticas que se plantearon en el movimiento estudiantil durante el período mencionado. Para ello se diseñan dos objetivos concretos: 1) describir y analizar la estructura de las reclamaciones del movimiento estudiantil en su doble perspectiva interpretativa: contra el modelo de desarrollo y contra la gestión del gobierno; y 2) describir y analizar las alternativas estratégicas planteadas en diversos momentos del movimiento estudiantil y cómo ello alienta la conformación de un movimiento social de amplio espectro en el país.

La metodología utilizada presenta al análisis cualitativo (estudio de procesos) como técnica principal. El resultado esperado en esta primera etapa y en el contexto de este trabajo, consiste en conocer las dimensiones articuladoras del movimiento estudiantil y social a partir de los resultados del análisis del conflicto y la percepción de los objetivos logrados. De esta manera, esperamos que el estudio arroje información pertinente para evitar caer en sobreestimaciones o subestimaciones de la acción de los sujetos involucrados en el proceso socio-político, considerando su proyección en el tiempo.

\section{Movimientos sociales: Discusión teórico-general}

En los años sesenta, cuando los movimientos sociales se constituyeron en representación de las crisis sociales en Europa y América Latina, parecía un estándar académico constatar la fusión de las esferas política y no política de la vida social a la hora de analizar cambios estructurales y políticos 
(Wallerstein, 2001; Cuninghame, 2010; Rojas Crotte, 1999). Al comenzar el siglo XXI hay muchos indicios que nos incitan a pensar que la historia del mundo entra en una nueva era, quizá prometedora, pero muy incierta como todas las que han producido grandes cambios históricos como en los siglos XIX y XX que desarrollaron procesos de crisis y mutaciones inimaginables y de mayor trascendencia, que en cualquier momento anterior de la historia del hombre contemporáneo (Hobsbawm, 1998).

El Estado capitalista opresor no soluciona los problemas de las personas involucradas. Grandes territorios de población empobrecida en el mundo predominan por sobre las potencias europeas, americanas y algunas otras naciones asiáticas. Transcurrido medio siglo, se está poniendo en cuestión la utilidad analítica constante de la dicotomía convencional entre "Estado" y "sociedad civil".

A partir de fines del siglo XX, varios gobiernos latinoamericanos iniciaron procesos encaminados a superar los efectos más devastadores de las políticas neoliberales ensayadas desde mediados de los ochenta. Partieron, casi todos, por cuestionar el automatismo de mercado y la subordinación acrítica a la lógica de la acumulación global e intentaron, con suerte y características diversas, restablecer el poder estatal para definir algunos rumbos centrales de su política económica y social.

Es decir, que tiende a desdibujarse la frontera que separa los asuntos y comportamientos "políticos" de los puramente "cívicos" (Guadalupe Vargas, 2003; Offe, 1996). Este diagnóstico nos conduce a explicitar el fenómeno consistente en el aumento de la actitud participativa de la sociedad civil. Lo que despierta en la gente la aspiración a conquistar sus derechos ciudadanos en un esquema de democracia cada vez más directa, tomando distancia de las instituciones clásicas de la representación como los partidos políticos y el Congreso. Todo ello en un ambiente de uso creciente de la protesta y las manifestaciones callejeras expresadas en movimientos sociales (Poratti, 2010; Cansino, 2012).

Al cumplirse más de dos décadas desde que Chile retomara su larga tradición en cuanto a organizarse sobre rieles participativos y, por lo tanto, democráticos, el país se encuentra en una situación paradójica. No cabe duda que la difícil transición del autoritarismo a la democracia fue exitosa. La gobernabilidad, sin embargo, se apoyó en los pilares legales y económicos construidos por el régimen autoritario, lo que no le permitió a Chile realizar profundos cambios en el ámbito de la superación de las inequidades y la marginalidad social.

Tal parece que la apuesta de la Concertación no fue tanto aplicar reformas enérgicas de una sociedad congelada por la vara autoritaria, sino emprender 
reformas de segunda o tercera generación, es decir retoques mediocres, en una sociedad que había experimentado una intervención neoliberal brutal que no sólo se instaló como etiqueta de comunicación y aceptación de la realidad entre los chilenos, sino que produjo una dialéctica de enceguecimiento a toda posibilidad de cambio sistémico, capaz de sepultar la consecuencia contradictoria del experimento autoritario: éxito económico, concentración de la riqueza, empobrecimiento de la clase media y desigualdad social severa.

Al transcurrir el tiempo se percibe, por una parte, un creciente desajuste entre una sociedad que ha experimentado cambios económicos y sociales; y estructuras y liderazgos políticos que, por otro lado, aparecen más y más distantes de la población en la base de su comportamiento social (Valenzuela, 2011).

Así las cosas, se perfila un modelo desastroso de des-democratización de la democracia, que desemboca en la configuración de movimientos sociales que reclaman a las elites un comportamiento sustantivamente democratizante. Es decir, hacer que las instituciones del Estado, que actúan en forma privada, actúen ahora en forma pública o eminentemente social.

Ahora bien, en la medida que la política pública afecta a los ciudadanos de manera más directa y visible, tratan los ciudadanos por su parte de lograr un control más inmediato y amplio sobre las elites políticas, poniendo en acción medios incompatibles con el sostenimiento del orden y la convención social (Drake y Silva, 1986). Esto representa evidentemente una inecuación cuyo origen tiene a las políticas públicas como factor principal y, por lo tanto, a las elites del Estado como responsables del desapego de la gente con la democracia y, en consecuencia, de la organización democrática como identidad política del Estado-nación.

Lo anterior podría entenderse como una postura academicista conservadora, en que la gobernabilidad del régimen democrático está definida puramente por el orden, algo así como un orden de instituciones funcionantes que no son resistentes al desgobierno. Así las cosas, una organización estatal a la usanza del siglo XX se traduce hoy en un Estado que conserva estructuras ineficientes para resolver los problemas de un mundo tecnológico y globalizado. Muchas causas explican este fenómeno, entre otras, la falta de conocimientos tecnológicos en la gestión de la administración pública, la ausencia de consensos, forma y ritmos de aplicar políticas públicas en un país de contrastes, como es el caso de Chile; las tentaciones populistas en el manejo de la caja fiscal y la corrupción estatal, entre otras.

Actualmente, el énfasis se coloca en un tipo de gobernabilidad en que las elites políticas democráticas son sustantivamente tales en cuanto se asocian a su capacidad incondicional de responder a las demandas sociales en forma 
práctica, des-burocratizada y responsable, es decir, haciendo acontabilidad (accountability) propiamente política. El término accountability, cuyo origen es anglosajón, se inscribe en el estudio de la desconfianza y sus expresiones institucionalizadas en la esfera pública, haciendo hincapié en la rendición de cuentas como necesidad para el adecuado funcionamiento del régimen democrático.

La separación del acto sustantivo de responsabilidad política y los asuntos sociales de quienes se dedican a la política es la clave central que explica el proceso que se vive actualmente en el mundo. Si esto es así, prima el fenómeno de la declinación de las instituciones de la democracia liberal y la configuración progresiva de grandes conflictos sociopolíticos: convulsiones sociales que establecen una independencia entre la cuestión social y las instancias de la representación como los partidos y la legislatura (Crouch, 2010).

Los partidos tienden a convertirse en un espacio no definido al interior del Estado des-democratizado. La representación de intereses se traduce en un rito electoral. La capacidad de las instituciones públicas de dar cuenta de sus responsabilidades sociales pierde sentido social en la misma medida que la burocracia del Estado se hace más pesada y torpe para servir a la población. Todo ello proporciona a la ciudadanía elementos que mueven en ella el interés por movilizarse.

Cabe ahora analizar la "nueva política" y los "nuevos movimientos sociales" del siglo XXI como un nuevo modelo socio-político en proceso de alineación con una sociedad cada vez más compleja en términos de resolver la ecuación entre mayores volúmenes de población y centralidad social, mayores demandas sectoriales, acumulación de riqueza económica y estructura desigualizante del modelo de desarrollo (Calderón y Szmukler, 2003). En definitiva, en la expresión de Lionel Barber, un mundo inconvencional (Barber, 2001; Bauman, 2002; Vásquez Roca, 2008). Para Barber, el año 2010 fue el año en que la sabiduría fue desafiada, redefinida e integralmente invalidada. Esto se puede apreciar en el explosivo crecimiento de facebook, twitter y otras "redes" sociales que cambiaron el lenguaje tradicional produciendo un nuevo prototipo en las preocupaciones de la actividad humana. Todo lo anterior lleva a una reestructuración de la interactividad humana anónima y sin conocimiento directo y verdadero del otro. Es la sociedad ignota, secreta, oculta, imaginante. Es decir la despersonalización genuina de la persona (Ponomarev, 2012).

La crisis financiera mundial tuvo efectos colaterales altamente controversiales en el campo del empleo y el desarrollo sectorial. El acceso al trabajo o la empleabilidad se hizo cada vez más abstruso. En 2011 estallaron los movimientos sociales de indignados o contrarios frente al sistema liberal competitivo de mercado. En Chile el protagonismo en este aspecto lo constituyeron los movimientos estudiantiles a partir de 2006 (Guillén, 2011; Heise, 2011). Los nuevos movimientos sociales que entran con fuerza con la 
llamada "revolución pingüina" ese año se alejan del populismo y del partido y van directamente a la demanda por eficacia de las políticas públicas, que interpelan al Estado a desarrollar el bienestar sin encapucharse en la burocracia ministerial. Se inspiran en la dialéctica de la restauración de un cierto orden social justo, equitativo, razonable e intentando liberar al ciudadano de la amenaza del "peligro social" (Bauman, 2002), propia de las democracias burocráticas, rígidas y de bajo impacto público.

La identidad, u orden racional, de los nuevos movimientos sociales es constituir la política en un derecho cívico consistente en recibir el impacto efectivo de un Estado social desburocratizado (Mazzuca, 2002). Es decir, un Estado sin otra función que hacer cosas sociales en todo lugar, sector o clima social, en donde el hecho social presenta deficiencias que entorpecen la preservación de la cultura libertaria en el acceso al bienestar.

\section{El movimiento estudiantil en Chile}

En el campo educacional en el gobierno de Aylwin se llevó a cabo un Programa de 900 escuelas piloto-rurales, que consistía en trabajar con el 10\% de las escuelas con más bajo rendimiento en el país, aplicando un programa de mejoramiento de las escuelas rurales. En el área del Estatuto Docente se redefinió el régimen laboral de los profesores desde el Código del Trabajo a un estatuto propio, se mejoraban las remuneraciones, incluyendo la estabilidad en los cargos. Se creó además un Programa de Mejoramiento de la Calidad y Equidad de la Educación (MECE), que apuntaba al perfeccionamiento de los profesores, y ayuda a los adultos a completar su educación.

Los objetivos de estas reformas eran crecer en equidad en la distribución de oportunidades educacionales, mejorar la calidad de la educación en escuelas básicas y medias y llevar a cabo una actualización de competencias para insertarse en el mercado laboral y para la continuación de estudios.

El resultado fue que estas medidas y programas se construyeron sobre las reformas de la dictadura, sin modificaciones más sustantivas al sistema de financiamiento, con limitaciones al rol regulador y fiscalizador del Estado, sin participación de los docentes, ni de la comunidad, que al fin de cuentas se transformaron en medidas parciales, en vez de avanzar a la equidad.

Para enfrentar esta realidad, el gobierno de Frei Ruiz-Tagle (1994-2000) planteó un fuerte aumento en el gasto en educación, apoyado por el mayor crecimiento económico que estaba viviendo el país, hecho que permitió avances concretos como la reforma curricular, extensión de la jornada escolar, aumento considerable de la estructura, fortalecimiento de la profesión docente y el llamado Proyecto Monte Grande. 
Ese proyecto consistía en la conformación de una red de establecimientos de enseñanza media de características especiales en términos de calidad a la atención de jóvenes de escasos recursos. La reforma del Estatuto Docente en 1995 benefició al profesorado con becas de perfeccionamiento y aumento de sueldos, aunque estos no quedaron satisfechos y manifestaron su inconformidad reiteradamente a través de una serie de huelgas

En el campo de la educación, el gobierno de Ricardo Lagos (2000-2006) llevó adelante la Jornada Escolar Completa (JEC). Promulgó las reformas constitucionales y una de ellas estableció la enseñanza media obligatoria y gratuita para todos los chilenos, cambiando el sistema de medición desde la Prueba de Aptitud Académica a la Prueba de Selección Universitaria. Esta transición entre una y otra prueba de medición para entrar a la universidad supuso una mayor igualdad en las oportunidades pero generó más polémicas que consensos, fundamentalmente porque constituían actos simbólicos de bajo y restrictivo impacto en los escolares puesto que aumentó la disparidad entre colegios particulares y los colegios municipales (Simonsen, 2013; Olivera Rivera, 2003; OPECH, 2006).

Bajo la Presidencia de Michelle Bachelet (2006-2010) un nuevo marco legal para la educación parvularia, básica y media se expresa en una Ley General de Educación (LEGE) que refuerza el derecho a la educación de calidad para todos, introduciendo el derecho universal a la educación gratuita, establecimiento de los estándares de aprendizaje y desempeño, no discriminación en procesos de selección y cambio curricular. La Ley crea el Sistema Nacional de Aseguramiento de la Calidad Educacional a través de la creación de la Agencia de Calidad y la Superintendencia de Educación, el Consejo Nacional de Educación y la reestructuración del Ministerio de Educación. Todo ello quedó en un ámbito meramente formal. Pero los estudiantes se dieron cuenta de las falencias de la educación en cuanto su eje de funcionamiento estaba construido a condición de pasar por el lucro del mercado, lo que creó un caldo de cultivo para la gestación de una máquina de desigualdades en la sociedad chilena nunca antes visto.

\section{La revolución escolar pingüina de 2006 como antecedente histórico inmediato de los sucesos posteriores}

El "movimiento pingüino" quedará como huella en la historia sociopolítica de Chile por los siguientes motivos: se constituyó en la primera manifestación masiva y de carácter nacional desde la restauración de la democracia en marzo de 1990. No por otra cosa se autodenominaron como "hijos de la democracia", puesto que pertenecieron a una generación que no conoció la 
dictadura, ni menos la "vieja democracia", sino sólo un régimen democrático que los afectó en sus intereses más fundamentales.

Además, se constituyó en un movimiento socio-político transversal y asociativo, en circunstancias que lo normal en esa época era escuchar de los jóvenes su distancia de la política tradicional. En tercer lugar la horizontalidad de su organización se apoyaba en nuevas tecnologías, lo que les permitía constituir y organizar el movimiento (García Huidobro S., 2006).

Las protestas de estos jóvenes aportan valor a la política educativa. Incorpora elementos organizados de la sociedad civil que transforma el movimiento estudiantil en un movimiento social que desde allí en adelante se hará cada vez más convergente. Es decir, desde los más diferentes grupos de intereses que no están de acuerdo con las más diversas políticas sectoriales de los gobiernos de la Concertación.

Si bien se tomó conciencia en equilibrar libertad de enseñanza y libertad en la educación, con un control efectivo del Estado, esta toma de conciencia llevó a la discusión acerca de quién enseña, qué se enseña y cómo fiscaliza el Estado en ambas dimensiones, asunto no resuelto por la autoridad.

A comienzos del año 2006 la Jefa de Estado intentó intimidar a los estudiantes movilizados y que habían removido la tensa calma reinante en el país hasta la fecha en muchos ámbitos del desarrollo sectorial. Chile había cruzado todo el período concertacionista esperando las reformas profundas a las que se había comprometido el arcoíris de la Concertación en los dos últimos años del régimen autoritario.

El hecho es que el 21 de mayo de ese año, a instancias del discurso sobre el estado de la nación, la Presidenta alertó a los estudiantes, expresándoles que aceptaba a los ciudadanos críticos, aquellos que plantean sus reivindicaciones, pero con espíritu constructivo, con propuestas y sin violencia. Pero, según los estudiantes, el espíritu constructivo debía haber partido desde la propia Jefa de Estado.

En una entrevista a la ex dirigente de los universitarios de 2011, Camila Vallejo expresó: "hubiese sido una buena señal dar una declaración con capacidad de autocrítica de lo que se hizo y de cómo ir avanzando realmente en superar esas fallas que tuvieron y que fueron profundas. La Concertación se equivocó en muchas cosas, en términos educacionales: todas las reformas que hizo fueron para consagrar el modelo heredado, profundizar la lógica del endeudamiento" (Vallejo, 2011).

La primera gran manifestación convocada por los estudiantes, ocurrió con posterioridad a los anuncios de la Jefa de Estado. Más de cien mil estudiantes de más de cien colegios del país se encontraban movilizados el 26 de mayo, 
es decir, poco antes del paro nacional de estudiantes, convocado para el martes 30 de ese mes y que contó con la adhesión de más de seiscientos mil escolares, convirtiéndose en la mayor protesta estudiantil de la historia de Chile, superando a aquellas que demandaban reformas en los años 6768; o las producidas en 1972 con motivo del proyecto de Escuela Nacional Unificada del Presidente Salvador Allende; o las que se produjeron por las políticas educacionales durante el régimen militar en 1980.

El modelo de desarrollo denominado "crecimiento con equidad" planteado por la Concertación tras 20 años de gobierno, muestra sus primeras señales de agotamiento. Los éxitos alcanzados en materia económica y de política fiscal tras la dictadura militar no condujeron a formas aproximadas de equidad. A través de un análisis crítico de los datos económicos y sociales, los "fantasmas del subdesarrollo" se expresan en la estructura productiva basada en productos primarios, mala calidad de la educación, peor aún en la salud, en el transporte público, injusta distribución de ingresos y baja inversión en ciencia y tecnología (Hunneus, 2000; Cañas Kirby, 1997; Garretón, 2012).

Chile cuenta con una extraordinaria situación patrimonial por ganancias obtenidas de las ventas del cobre, pero choca con una clase política temerosa de tomar decisiones de cambio al modelo político heredado del régimen autoritario y renuente a emprender las necesarias reformas económicas para pasar a una siguiente etapa de desarrollo con mayor valor agregado (Cleary, 2007; Sunkel, 2006).

El capitalismo neoliberal "a forti" aplicado en Chile cubrió todo el espectro económico: desde servicios básicos, como el agua, la salud, la vivienda, el sistema de carreteras. La educación aceptó los términos del juego y se constituyó en el punto de ruptura entre los estudiantes y el Estado. Sin embargo en 2006, los estudiantes tomaron conciencia de la empobrecida y mediocre forma de recibir educación, patearon el tablero y pelearon para mejorarla. Hay que recordar que hasta antes de 1973 la educación se había tratado de empinar como uno de los pilares del desarrollo, especialmente a partir de 1938. El slogan de los gobiernos radicales era "gobernar es educar".

En definitiva, el criterio que se dejó desarrollar como herencia de la dictadura y que no fue modificado por la Concertación ni menos por el gobierno de Sebastián Piñera (2010-2014) fue la dictadura del mercado para la educación, proceso personificado en sujetos que pueden construir en Chile un supermercado de la educación escolar a partir de la municipalización de la educación, retratada en la Ley Orgánica Constitucional de Enseñanza publicada en marzo de 1990, que entregó la administración de las antiguas escuelas estatales a los Municipios (Contreras y Huneeus, 2010). 
El empobrecimiento de la educación chilena se debió a su alejamiento forzoso desde la administración central del Estado (política que primó entre 1938 y 1973) a la de las municipalidades. Los colegios públicos, salvo excepciones como el Instituto Nacional, se transformaron en sitios donde los profesores "hacen como que enseñan y los alumnos hacen como que aprenden (Nitrihual, 2009). Todo lo anterior ha sido un problema histórico en Chile. La educación es el ícono que ilustra la desigualdad y la posterior creación de brechas sociales, lo que produce un efecto desigualizante a partir de una cultura de consumo en la sociedad chilena.

Cabe recapitular que el movimiento "pingüino" del año 2006 reclamó, junto a la derogación efectiva de la LOCE, la derogación del Decreto 524 del 11 de marzo de 1990, que regula los centros de alumnos; el fin efectivo a la municipalización de la enseñanza; reformulación de la Jornada Escolar Completa; gratuidad de la prueba de selección universitaria; pase escolar gratuito y unificado; tarifa escolar gratuita en el transporte para la educación media.

Las propuestas del gobierno de Michelle Bachelet, anunciadas en junio de 2006, fueron rechazadas por la Asamblea Nacional Estudiantil, convocando a paro el 5 de junio. Tras esta movilización el movimiento perdió fuerza y finalmente los estudiantes anunciaron el fin de la principal ola de movilizaciones el 9 de junio de 2006.

El "movimiento pingüino" quedará como huella en la historia sociopolítica de Chile por los siguientes motivos: se constituyó en la primera manifestación masiva y de carácter nacional desde la restauración de la democracia en marzo de 1990. No por otra cosa se autodenominaron como "hijos de la democracia", puesto que pertenecieron a generación que no conoció la dictadura, ni la vieja democracia, sino sólo un régimen democrático que los afectó en sus intereses más fundamentales. Además, se constituyó en un movimiento político, en circunstancias que lo normal en esa época era escuchar de los jóvenes su distancia de la política. En tercer lugar, la horizontalidad de su organización se apoyaba en nuevas tecnologías, lo que les permitía constituir y organizar el movimiento (García Huidobro, 2006).

En fin, si bien con la "revolución pingüina" se tomó conciencia en equilibrar libertad de enseñanza y libertad en la educación, con un control efectivo del Estado, esta toma de conciencia llevó a la discusión acerca de quién enseña, qué se enseña y cómo fiscaliza el Estado en ambas dimensiones, asunto no resuelto por la autoridad.

\section{Una nueva generación estudiantil}

Con las oleadas de movilizaciones de 2011 brotaban las genuinas contradicciones de la sociedad chilena, cuestión que volvió a involucrar al país 
en los procesos sociales de la región, con sus lógicas y contextos propios. A partir del otoño de ese año, el país se vio ataviado por uno de los momentos más monumentales de su historia desde el retorno a la democracia en 1990. Las protestas semanales se transformaron en un proceso de creciente movilización estudiantil, al que se plegaron muchos otros actores de la sociedad que anunciaban la primera gran demanda social chilena. Los esfuerzos del movimiento estudiantil se orientaron a presionar al gobierno de Sebastián Piñera de manera de poner en marcha una amplia gama de reformas educativas capaces de poner fin a las instituciones lucrativas de educación y ofrecer un mayor acceso a una educación de calidad.

Un grupo del influyente The Tufts Daily en Chile señaló -de acuerdo a sus mediciones- que el grado de participación de los estudiantes y la movilización social de amplio espectro que provocó no era comparable a cualquier forma de participación de grupos sociales en los Estados Unidos. Esto constituye un síntoma palmario del sentimiento de injusticia social que se dilata cada vez más en la sociedad chilena. Chile es el país con menor gasto público en los cuatro niveles de educación (pre-primaria; primaria; secundaria y superior) con un 57,9 por ciento frente a los otros 33 países que son parte de la OCDE. Finlandia es el país con mayor gasto público, con un 97,6 por ciento (OCDE, 2010).

En este trabajo hemos planteado la discusión principal acerca de las formas de gatillamiento y desarrollo de un movimiento estudiantil que, en forma transversal y sin precedentes, transitó de un fenómeno gremial-sectorial a un mega-fenómeno político-público, levantando una voz potente de protesta contra un sistema de educación de mercado que se proyectó al resto de la sociedad. ¿Es que durante su gestión de dos décadas, los líderes de la Concertación por la Democracia no habían tenido motivaciones realmente democratizantes o se conformaron con la inviabilidad del cambio a causa de factores político-institucionales que frenaban las reformas comprometidas a instancias del plebiscito presidencial de octubre de 1988? ¿O es que la Concertación vivió una desenfrenada experiencia de persuasión hacia el modelo heredado del gobierno de Pinochet y, conforme pasaba el tiempo, se impregnó de una brutal idiosincrasia de mercado?

Las dimensiones del movimiento estudiantil del 2011 adoptaron un carácter tan intensivo y extensivo que se produjo un ensanchamiento de la protesta inicial hacia una gran mayoría de la sociedad chilena, que finalmente optó por sumarse a las reclamaciones sociales en los más diversos aspectos sectoriales y desde posiciones políticas aparentemente autónomas de los grandes mundos políticos predominantes en Chile.

En tal situación, los movimientos sociales del 2011 hacen aflorar como nunca antes la urgencia de realizar transformaciones estructurales que no están en manos de la política ni de los políticos tradicionales, entrampando 
todo el sistema político y la necesidad de revisitar los fundamentos de la democracia, tal cual la conocemos. Parece rondar una incertidumbre entre quienes buscan una postura definitiva acerca del origen del estallido social de 2011. La sorpresa ocurrida entre mayo y diciembre de ese año se produce en un Chile político que había cambiado vertiginosamente, justo en medio de la catástrofe de un gran terremoto.

Ni en la coalición gobernante ni en la oposición se previó la magnitud de lo que sucedería con los estudiantes, cuya acción tendría impacto en otros grupos de intereses de la sociedad, produciéndose así un fenómeno de agregación de otros actores sociales en el proceso histórico de reclamaciones contra el funcionamiento de la democracia liberal.

\section{Las Demandas de los Estudiantes agrupados en la CONFECH}

Esa es la razón por la cual los estudiantes reclaman la recuperación de la Educación Pública como piedra angular de las demandas estudiantiles. Esto se manifiesta para ellos en la necesidad de que en el sistema educativo del país exista un fin del lucro efectivo, puesto que no se entiende que la generación y transmisión del conocimiento constituya simplemente una mercancía.

La relación estudiante-profesor no debe tergiversarse con la relación cliente-proveedor. A su vez, no parece lógico que la investigación y la creación estén supeditadas al retorno de utilidades puesto que daña la generación de conocimiento útil para la sociedad y la cultura emancipadora.

Todo ello significaba en 2011 que recuperar la educación pública se manifestara en tener como horizonte una educación estatal gratuita, siendo el Estado el primer responsable de asegurar la educación como un derecho. Más aún en un país en donde existen riquezas que pueden financiarla. Los estudiantes tenían claro que lamentablemente dichos recursos se encuentran en manos de privados y transnacionales, que acumulan suculentas ganancias en desmedro de los derechos sociales. Ello hace necesario a su vez, realizar en Chile una reforma tributaria, que permita al Estado financiar de manera óptima los derechos que debe garantizar, como la salud y la educación.

Entonces, los estudiantes entendían que la educación se encuentra en una profunda crisis, lo que quedaba en evidencia en una pésima calidad en muchas instituciones de educación superior, el poco acceso al sistema de los sectores más vulnerables, el excesivo endeudamiento de las familias, el debilitamiento del rol del Estado y sus instituciones, la generación de lucro -fuera de la ley- por parte de muchas instituciones privadas y la prohibición explícita de la participación de la comunidad universitaria en el desarrollo de 
las instituciones. Las responsabilidades políticas de esta crisis tienen su origen en la dictadura militar, que desmembró el sistema educativo y lo abrió a los intereses empresariales. Pero también, dicha responsabilidad se arrastra hacia todos quienes administraron el sistema e incluso fueron profundizándolo. Los gobiernos de la Concertación y el Gobierno de Sebastián Piñera (20102014) fueron profundizadores del modelo y lo que reclaman los estudiantes de Chile es un profundo cambio al sistema educativo.

De manera más específica, las demandas de los estudiantes universitarios eran (son) las siguientes:

-Acceso con equidad, calidad, integración y heterogeneidad social en la matrícula.

-Rechazo a la PSU por su carácter regresivo, que no logra captar los talentos de nuestro país, sino que detecta el nivel socioeconómico; creación de mecanismos complementarios de acceso que consideren nivelación, mantención y titulación, para que de una vez exista igualdad de oportunidades para todos (Ejemplo: propedéuticos).

-El acceso debe asegurarse hacia instituciones de calidad, que posibiliten no sólo una formación de profesionales y técnicos de excelencia académica y técnicos de excelencia en el marco del pluralismo y la tolerancia y los valores de justicia e igualdad, lo que requiere nuevos estándares de calidad donde no se mida la gestión institucional, sino los perfiles profesionales y el aseguramiento de la libertad de cátedra y opinión. La acreditación debe estar asociada a la transparencia en el uso de recursos públicos, de manera de evitar aquellas instituciones que lucren evadiendo la ley.

- Garantizar el acceso y las condiciones de estudio para las personas con discapacidad en la educación superior.

-Aumentar el financiamiento público en Educación Superior como porcentaje del PIB.

-Fondo de revitalización para las Universidades Tradicionales, que hoy deben competir contra grandes conglomerados económicos, amordazados por su burocracia interna, el autofinanciamiento y alto nivel de endeudamiento. Este sería por una vez y orientado con prioridad para aquellas instituciones de carácter Estatal, de Regiones y aquellas que acogen a los estudiantes más vulnerables.

-Reestructuración integral del sistema de becas y ayudas estudiantiles, en pos de terminar con el sistema basado en el endeudamiento familiar, asegurando que las becas para los tres primeros quintiles cubrirán la totalidad de sus aranceles y para el cuarto y quinto quintil ser diferenciado según su capacidad de pago. Además las becas de mantención y alimentación deben 
ser reajustadas acorde a la realidad nacional y se debe aumentar la cobertura al tercer quintil y parte del cuarto, que hoy sí son vulnerables porque su financiamiento se basa en la deuda con tasas de interés impagables.

-Tarjeta nacional estudiantil única y estatal, válida los 365 días del año, en todo el territorio nacional.

-Eliminación del Aporte Fiscal Indirecto, por ser un claro incentivo regresivo que fomenta la segregación estudiantil.

-El Estado debe asumir la responsabilidad de realizar formación técnica a través de sus instituciones, no dejando este ámbito de la educación en manos del mundo privado.

-Derogación del DFL 2 de 2010, artículo 56 letra e), artículo 67 letra e), y artículo 75 letra e). Exigir el derecho a la participación triestamental de todas las instituciones de Educación Superior en sus cuerpos colegiados, en las elecciones de autoridades unipersonales y en la toma de decisiones.

- Asegurar las libertades de expresión, cátedra y de asociación a estudiantes, docentes y trabajadores en todas las instituciones, para que no se sigan violando los derechos constitucionales (Confederación de Estudiantes de Chile, 2011).

Destacan además el requerimiento de una Superintendencia de Educación Superior, democratización para facilitar la participación de todos los estamentos, reconocimiento a los pueblos originarios y la creación de centros de formación técnica e institutos profesionales estatales.

\section{La respuesta del gobierno}

Después de la entrega del documento del ejecutivo el $1^{\circ}$ de agosto, que contemplaba 21 puntos claves que darían respuesta a la $\mathrm{CONFECH}$, se trasluce el perfil pragmático del nuevo ministro de Educación. Su vocación legislativa queda en evidencia, tras analizar el documento que detalla las intenciones del gobierno para buscar solución a un conflicto que lo ha mantenido en jaque, reflejado encuesta tras encuesta, tal como se puede ver en la última de ADIMARK en la que presenta nada menos que un $62 \%$ de desaprobación a su gobierno.

De los 21 puntos, al menos 10 otorgaron una respuesta positiva, aun cuando simplemente ritual o formal a las demandas estudiantiles en lo que refiere al sistema de becas, desmunicipalización, acreditación e integración, así como también la creación de una superintendencia, lo que en proporción, alcanzaría la mitad de su petitorio. 
Con respecto a poner fin al lucro en la educación, bandera de lucha del movimiento estudiantil y principal piedra de tope entre los estudiantes y el gobierno, el documento afirma que la creación de una Superintendencia de Educación Superior sería clave en el cumplimiento de las disposiciones legales que irían al frente de la censura de esas prácticas. No obstante, el ejecutivo no hacía mención directa a la privación de actividades de las instituciones de educación superior que perciben utilidades que no son reinvertidas íntegramente en el proceso educativo.

\begin{tabular}{|c|c|}
\hline Lo que exigen estudiantes y profesores & Lo que propone el Ejecutivo \\
\hline $\begin{array}{l}\text { Sistema Nacional de Educación Pública, } \\
\text { Gratuita, Democrática y de Calidad, } \\
\text { organizado y financiado por el Estado en } \\
\text { todos sus niveles, es decir, desde la cuna en } \\
\text { adelante, asumiendo un proceso continuo } \\
\text { en su formación. }\end{array}$ & $\begin{array}{l}\text { Derecho a una educación de calidad, } \\
\text { estableciendo el deber del Estado de } \\
\text { velar por el mismo. } \\
\text { Aumentar cobertura y calidad de la } \\
\text { educación parvularia. }\end{array}$ \\
\hline $\begin{array}{l}\text { Sistema Nacional de Educación Pública, } \\
\text { desmunicipalización. }\end{array}$ & $\begin{array}{l}\text { Aumentar el gasto en subvención } \\
\text { escolar en los alumnos más } \\
\text { vulnerables. } \\
\text { Desmunicipalizar gradualmente la } \\
\text { educación escolar estatal. }\end{array}$ \\
\hline $\begin{array}{l}\text { Nuevo sistema de financiamiento que } \\
\text { asegurará un aporte basal y suspensión } \\
\text { inmediata de la creación de nuevos } \\
\text { establecimientos subvencionados. Servicio } \\
\text { eficiente y suficiente de transporte escolar } \\
\text { gratuito y seguro. }\end{array}$ & $\begin{array}{l}\text { Modificar el Sistema de aseguramiento } \\
\text { de la calidad de la educación } \\
\text { escolar y sistema de fiscalización del } \\
\text { cumplimiento normativo del sistema } \\
\text { de financiamiento escolar. }\end{array}$ \\
\hline $\begin{array}{l}\text { Carrera profesional docente basada en el } \\
\text { mérito y la experiencia, dignificación de sus } \\
\text { remuneraciones. }\end{array}$ & $\begin{array}{l}\text { Modernizar la carrera docente y } \\
\text { fortalecer la formación inicial de } \\
\text { profesores. }\end{array}$ \\
\hline $\begin{array}{l}\text { Sistema de financiamiento propio para la } \\
\text { educación técnico-profesional o politécnica. }\end{array}$ & $\begin{array}{l}\text { Fortalecer la oferta educativa de la } \\
\text { educación escolar técnico-profesional. }\end{array}$ \\
\hline $\begin{array}{l}\text { Plan Nacional de Reconstrucción y } \\
\text { Habilitación de Infraestructura Escolar. }\end{array}$ & $\begin{array}{l}\text { Máxima celeridad en la reconstrucción } \\
\text { de los establecimientos educacionales. }\end{array}$ \\
\hline $\begin{array}{l}\text { Democratización para la participación } \\
\text { estudiantil secundaria y superior. }\end{array}$ & $\begin{array}{l}\text { Derogar las normas que limitan la } \\
\text { participación estudiantil en educación } \\
\text { superior. }\end{array}$ \\
\hline $\begin{array}{l}\text { Creación de un Aporte Basal a las } \\
\text { Universidades Públicas. }\end{array}$ & $\begin{array}{l}\text { Fortalecer la educación superior estatal } \\
\text { y las universidades tradicionales, a } \\
\text { través de aportes basales contra metas } \\
\text { de interés nacional y regional. }\end{array}$ \\
\hline
\end{tabular}




\begin{tabular}{|c|c|}
\hline $\begin{array}{l}\text { Aumento de los Aportes Fiscales } \\
\text { Directos, Fondo de revitalización para } \\
\text { las Universidades Tradicionales, de libre } \\
\text { disposición, reestructuración total del } \\
\text { sistema de educación superior enfocando a } \\
\text { la gratuidad en su totalidad para todas las } \\
\text { universidades del CRUCH. }\end{array}$ & $\begin{array}{l}\text { Complementar el financiamiento a las } \\
\text { instituciones de educación superior } \\
\text { con aportes asociados a convenios de } \\
\text { desempeño, fomentando el desarrollo } \\
\text { de áreas específicas. Salto cualitativo } \\
\text { en innovación, ciencia y tecnología. }\end{array}$ \\
\hline $\begin{array}{l}\text { Sistema de becas para todos los estudiantes } \\
\text { provenientes de familias del } 70 \% \text { de } \\
\text { menores ingresos pertenecientes a las } \\
\text { instituciones privadas no tradicionales. } \\
\text { sistema único de fondo solidario para el } \\
30 \% \text { restante de los y las estudiantes de } \\
\text { Chile que estén dentro de las instituciones } \\
\text { privadas que no lucren, ampliar cobertura } \\
\text { de ayudas estudiantiles a la totalidad de los } \\
\text { y las estudiantes del país. }\end{array}$ & $\begin{array}{l}\text { Aumentar las becas, rebajar el costo } \\
\text { del crédito con aval del Estado y } \\
\text { reprogramar los deudores morosos } \\
\text { del crédito solidario. Reestructurar } \\
\text { el sistema de becas y créditos } \\
\text { estudiantiles para la educación } \\
\text { superior. }\end{array}$ \\
\hline $\begin{array}{l}\text { Acreditación obligatoria para todas las } \\
\text { instituciones de Educación Superior y sus } \\
\text { carreras, a través de agencias públicas, } \\
\text { autónomas y transparentes. }\end{array}$ & $\begin{array}{l}\text { Reformular y hacer más exigente } \\
\text { el sistema de acreditación de la } \\
\text { educación superior. }\end{array}$ \\
\hline $\begin{array}{l}\text { Crear una superintendencia de educación } \\
\text { superior. Ausencia total de fin de lucro. } \\
\text { Transparencia total del uso de sus recursos } \\
\text { financieros. }\end{array}$ & $\begin{array}{l}\text { Crear una superintendencia de } \\
\text { educación superior que regule el } \\
\text { cumplimiento de la ley. }\end{array}$ \\
\hline $\begin{array}{l}\text { Creación de mecanismos complementarios } \\
\text { de acceso a la PSU, de público } \\
\text { conocimiento y debidamente informados, } \\
\text { que consideren ranking, propedéuticos y } \\
\text { procesos de nivelación. }\end{array}$ & $\begin{array}{l}\text { Sistema de admisión a la educación } \\
\text { superior más equitativo e inclusivo, } \\
\text { considerando elementos como el } \\
\text { ranking escolar. }\end{array}$ \\
\hline $\begin{array}{l}\text { CFT e IP con fines de lucro no podrán } \\
\text { percibir beneficios del Estado. El Estado } \\
\text { deberá asegurar la presencia de oferta } \\
\text { educativa estatal de centros de formación } \\
\text { técnica e institutos profesionales en todas } \\
\text { las regiones del país, creando una Red } \\
\text { Nacional de Educación Técnica gratuita y de } \\
\text { calidad. }\end{array}$ & $\begin{array}{l}\text { Potenciar una oferta de calidad y alta } \\
\text { pertinencia en la educación superior } \\
\text { técnico-profesional. }\end{array}$ \\
\hline $\begin{array}{l}\text { Universidad Estatal pública e Intercultural, } \\
\text { Aumento en el monto de la Beca } \\
\text { Indígena y en la cantidad de beneficiarios; } \\
\text { reconocimiento jurídico de los espacios } \\
\text { utilizados por estudiantes indígenas. }\end{array}$ & $\begin{array}{l}\text { Promover la interculturalidad en la } \\
\text { educación superior. }\end{array}$ \\
\hline
\end{tabular}

Fuente: Consorcio de Universidades del Estado de Chile, 2 de agosto de 2011. 


\section{Las movilizaciones}

Fue en este período en que se gatilló el tema de la gratuidad y extensión de los pases escolares de transporte. La fase de crecimiento se expresó en la demanda por una educación pública, gratuita, de calidad, participativa y democrática. La manifestación de los estudiantes y la innovación en la forma de llevarlas a cabo, encantó a otros grupos sociales independientes de los estudiantes y se adhirieron a las marchas.

El gobierno aún no dimensionaba en toda su magnitud lo que estaba ocurriendo y fue sobrepasado. La fuerza que adquirieron las movilizaciones transcurría junto a las huelgas de hambre y la toma de establecimientos educacionales. Todo ello hizo caer al ministro de Educación Felipe Bulnes y provocó el descenso de la popularidad del presidente Sebastián Piñera.

A medio año de iniciado el conflicto el gobierno y la oposición a él no pudieron solucionarlo y ni siquiera canalizarlo, lo que tuvo como efecto la caída transversal en la credibilidad del poder ejecutivo y el cansancio de los estudiantes. La sociedad en su gran mayoría siguió otorgándole un significativo apoyo al movimiento estudiantil.

No obstante, este fue decreciendo por las acciones, principalmente de violencia, que fueron escalando en espiral durante todo el año 2011. Los estudiantes se enfrascaron en el tema acerca de si seguir o no seguir con las movilizaciones, si ceder o no en puntos específicos, si ocupar o no las instituciones, si rechazar o no las negociaciones entre gobierno y oposición, si seguir sosteniendo o no a ultranza la gratuidad total.

El conflicto fue desactivado sin ser resuelto, lo que puso sobre la tabla de las hipótesis, la reactivación de las manifestaciones -como sucedería- hacia los próximos años (Schmal \& Arroyo, 2012; Brunner, 2011; Waissbluth, 2011), especialmente con los estudiantes universitarios, cuyos líderes recientemente electos representan posiciones de izquierda y visiones anarquistas en las cuestiones políticas. La estudiante de arquitectura Naschla Aburma, electa a fines de 2013 como presidenta de la FEUC aseguraba que el movimiento estudiantil va a seguir movilizándose independientemente del gobierno recién elegido y asumido en marzo de 2014.

Los principales representantes de los estudiantes secundarios y universitarios, reunidos en la ACES y la Confech, criticaron el programa de gobierno presentado por la entonces candidata presidencial del pacto Nueva Mayoría, Michelle Bachelet. El presidente de la Federación de Estudiantes de la Universidad Católica (FEUC), Diego Vela, aseguraba que "para (que ocurran) los cambios en Chile, se necesita no quedar bien con todos, sino que buscar el bien de todos". 
En tanto, la vocera de la ACES, Isabel Salgado, señaló que "hay una desconfianza de los estudiantes secundarios sobre el programa de Bachelet (...) si durante 20 años la Concertación no realizó los cambios, nada nos garantiza que ahora lo van a hacer" (El Mostrador, 2013).

En definitiva, las movilizaciones estudiantiles que se inician en 2006 y que en 2011 tuvieron un efecto contagio expresado en la agregación de otros grupos sociales no necesariamente provenientes de los colegios y universidades, tuvieron un factor genético que se puede resumir en los siguientes aspectos:

-Las grandes brechas sociales imperantes en Chile provocadas por los efectos desigualizantes del mercado. En el ámbito del financiamiento, se observa un alto endeudamiento a nivel universitario. No hay país en el mundo donde la carga del costo de educar recaiga tan fuertemente en las familias, mientras el Estado hace el papel de ciego y sordo en esa situación.

-Otra causa de las movilizaciones estudiantiles se relaciona con la mentalidad neoliberal pragmático-utilitarista heredada desde la base ideológica de libre mercado aplicada a partir de los primeros años de la dictadura, hacia 1976, atravesando los gobiernos de la Concertación y hasta el gobierno de Sebastián Piñera. Ello tuvo su impacto en la educación.

- Una cuarta causa tiene que ver con el funcionamiento del modelo neoliberal en base al lucro, que tropieza con la buena calidad de la productividad a causa de la apertura de brechas sociales, lo que constituye un espolonazo a la capacidad del país de tener una buena educación.

Todo lo anterior produjo en 2011 un efecto de agregación de otros grupos sociales que se alinearon en acciones colectivas produciendo el gran movimiento social entroncado en el movimiento estudiantil. Ello no sólo fue visto en Chile, sino que también en otros países del mundo. Surgen así las redes sociales a partir del uso de las tecnologías. La sociedad se organiza con recurso a ellas, acortando el tiempo para cohesionar la acción social movimental de los diferentes grupos de interés. La autoridad gubernamental no puede contener la acción de protesta frente a esta nueva estrategia. El Estado queda inmovilizado y sólo le queda recurrir a la fuerza polić́aca para reprimir a la sociedad de manera física y simbólica.

\section{Conclusión}

La tragedia y la fatalidad de Chile se expresan en algunas de las características que hemos analizado en este trabajo. Instalamos una pregunta principal que se tradujo en un planteamiento de nuestro problema, que constituye en realidad el problema que el país deberá resolver en los próximos años. 
Los chilenos deberán aprender a socializar un modelo de organización y convivencia social no excluyente, no polarizada.

Ninguna sociedad puede llegar a sostenerse sobre la base de la tensión constante que significa una estructura confusa basada en la polarización de ideas y proyectos de desarrollo que nunca convergen entre sí. Chile no podrá alcanzar metas de desarrollo aplicando conductas segregativas, que impidan la interacción entre los diferentes mundos sociales que componen el país.

Es muy probable que el aparato presidencial ya electo en segunda vuelta en diciembre de 2014, no tenga la inteligencia ni la fuerza suficiente para resolver la tragedia de Chile, que hemos estado comentando. El gran conflicto entre gobierno y estudiantes "terminó" en 2011, pero sin resultados apenas atractivos para los movilizados y con un fuerte fracaso para las instituciones de la democracia.

Chile se encuentra en un estrecho despeñadero que en los próximos años movilizará a sus ciudadanos a enfrentar grandes riesgos. El eje de tales riesgos será la prolongación de la desconfianza desbordada entre las alternativas en juego. Pero si las alternativas no se construyen en una sociedad que actúa asociadamente, no habrá juego, sino periplo y permanente desorden.

\section{Referencias bibliográficas}

a) Artículos

Aguilar Solé, S. (2001). "Movimientos Sociales y Cambio Social: ¿Una lógica o Varias Lógicas?", en Revista Internacional de Sociología, 30, pp. 29-62.

Barber, L. "Siete temas que delinearon el 2010: año de lo inconvencional", en Financial Times, 3 de enero de 2011.

Calderón, F. y Szmukler, A. (2003). "Globalización y Nueva Complejidad Social", en Revista Aportes Andinos, 6, Universidad Andina Simón Bolívar.

Cansino, C. (2013). "Democratizando la Democracia: De la Primavera árabe a los Indignados", en Tla-Melaua, 34, Puebla: Benemérita Universidad Autónoma de Puebla, pp. 26-44.

Cleary, E. (2007). "Chile, entre la imagen de éxito y los fantasmas del subdesarrollo", en Polis, 18, en https://polis.revues.org/4145, revisado el 18 de octubre de 2015.

Cuninghame, P. G. (2010). "Resistiendo al Imperio. Autonomía, Autonomismo y Movimientos Sociales Latinoamericanos", en Revista del Pensamiento Sociológico, pp. 149-166. 
Falabella, A. (2008). "Democracia a la Chilena. Un Análisis del Movimiento estudiantil y su desenlace", en Docencia, 36. Santiago: Universidad Alberto Hurtado pp. 5-17.

Guadalupe Vargas, J. (2003). "Teoría de la Acción Colectiva: Sociedad Civil y Movimientos Sociales en las nuevas formas de gobernabilidad en Latinoamérica", en Nómadas, Revista Crítica de Ciencias Sociales y Jurídicas, 7. Madrid: Universidad Complutense de Madrid.

Margotta T, C. (2008). "Chile y La Educación Universitaria: ¿Derecho o Privilegio?", en Altering for América Latina. Paris: Diffusion de L"Information sur L'Amerique Latine/ Berenguer-Globenet.

Mazzuca, S. (2002). "¿Democratización o Burocratización? Inestabilidad del acceso al poder y estabilidad del ejercicio del poder en América Latina», en Araucaria, 7, año 4. Sevilla: Universidad de Sevilla.

Nitrihual, L. (2009). "Lo reversivo en la revolución de los secundarios en Chile", en Quorum Academico, 6 (1). Venezuela: Universidad del Zulia, pp, 121-135.

Paredes, J. P. y A. Elizalde (2011). "Lógicas Colectivas y Nuevas Formas de Politicidad", en Polis, 10, № 28. Santiago: Universidad Bolivariana, pp. 7-13.

Simonsen, E. "La reforma educacional 'a la chilena' de Waisbluth", en La Tercera, 7 de septiembre de 2013.

Thielemann H., L. (2012). "Para una periodificación del Movimiento Estudiantil de la Transición (1987-2011)", en Sistematización de talleres para la acción estudiantil. Santiago: Centro de Estudios Fech, pp. 32-51.

Vallejo, Camila (2011). "Bachelet tiene una responsabilidad de lo que pasó en la revolución pingüina", en http://www.elmostrador.cl/noticias/pais/2011/12/30/ camila-vallejo-bachelet-tiene-una-responsabilidad-de-lo-que-paso-con-la-revolucion-pinguina, revisado el 15 de diciembre de 2015.

Vásquez Roca, A. (2008). "Zygmunt Bauman: Modernidad Líquida y Fragilidad Humana", en Nómadas: Revista Crítica y Ciencias Sociales y Jurídicas. Madrid: Universidad Complutense de Madrid.

Waissbluth, M. (2011). "Manifestaciones estudiantiles en Chile" en Foreign Affairs Latinoamérica, 11, 4, pp. 32-39.

\section{b) Libros}

Allende, S. (1971). Discurso de Apertura del Año Escolar. Santiago: Universitaria.

Bauman, Z. (2002). Las consecuencias perversas de la modernidad. Barcelona: Paidós. 
Boeninger, E. (1968). Programa para una Universidad de Chile Crítica, Pluralista y Creadora. Editorial Universitaria.

Brunner, J. J. (2011). El conflicto de las universidades: entre lo público y lo privado. Santiago: UDP.

Cálix R., Á. (2010). Emancipación y Cambio Social: la acción colectiva de los movimientos sociales. Tegucigalpa DC.: Friedrich Ebert Stiftung.

Cañas Kirby, E. (1997). Proceso Político en Chile: 1973-1990. Santiago: Andrés Bello.

Casals Araya, M. (2010). El Alba de una Revolución: 1956-1970. Santiago: Lom. Confederación de Estudiantes de Chile (2011). Demandas de los Estudiantes Agrupados en la CONFECH.

Contreras, D. y Huneeus, F. (2010). El lucro en la educación escolar. Evidencias y Desafios Regulatorios. TIPS N¹0, Departamento de Economía, Universidad de Chile.

Crouch, C. (2010). Posdemocracia. México: Taurus.

Cruz Coke, R. (1984). Historia Electoral de Chile 1925-1973. Santiago: Editorial Jurídica de Chile.

Drake, P. \& Silva, E. (1986). Elections and Democratization in Latin América. San Diego.

Edwards Vives, A. (1928). La Fronda Aristocrática en Chile. Santiago: Imprenta Nacional.

García Huidobro S., J. E. (2006). ¿Qué nos dejó la movilización de los pingüinos? Santiago: Documento de Trabajo del Consejo Asesor para la Calidad de la Educación, S/N.

Garretón, M. A. (2012). Neoliberalismo corregido y progresismo limitado: los gobiernos de la Concertación en Chile 1990-2010. Santiago: Arcis-Clacso.

Heise, H. (2011). European Governance: Institutionelle Reformen nach der Krise. Hamburg: Wistschaftsdiens.

Hobsbawm, E. (1998). Historia del Siglo XX. Buenos Aires: Crítica.

Hunneus Madge, C. (2000). El Régimen de Pinochet. Santiago: Editorial Sudamericana.

Macadam, D. e. (1999). Movimientos Sociales: Perspectivas comparadas. Madrid: Istmo.

Mayol, A. (2012). No al Lucro. Santiago: Debate. 
Meller, P. (1996). Un siglo de economía política chilena: 1890-1990. Santiago: Andrés Bello.

Millas, H. (1983). Habráse Visto. Santiago: Andrés Bello.

Moraga Valle, F. (2007). "Muchachos Casi Silvestres". La Federación de Estudiantes y el Movimiento Estudiantil Chileno 1906-1936. Santiago: Universidad de Chile.

Moulian, T. (2006). Fracturas: De Pedro Aguirre Cerda a Salvador Allende ( 19381973). Santiago: Lom.

Offe, C. (1996). Partidos Políticos y nuevos movimientos sociales. Madrid: Editorial Sistema.

Ponomarev, A. (2012). Balancing Internet Regulation and Human Rights. Stockholm: Stockholm University 1.

Poratti, G. (2010). El Shock del S. XXI. Buenos Aires: Universitaria.

Salazar, G. (1986). De la Generación Estudiantil del 68. Santiago: Editorial Sur.

Schmal, R. y Arroyo, P. (2012). Las Movilizaciones estudiantiles en Chile durante el 2011 y los escenarios que se abren para el presente año. Arica: Documento para la Asamblea FAUECH.

Touraine, A. (1998). The Voice and the eye. An analysis of social movements. Cambridge: Cambridge University Press.

Traugott, M. (2002). Protesta Social. Barcelona: Hacer.

Valenzuela, A. (2011). Crisis de Representación y Reforma Política en Chile. Santiago: CEP-CIEPLAN.

Varios autores (2001). Historia del Siglo XX Chileno. Santiago: Sudamericana.

Vitale, L. (1998). Contribución a una historia del anarquismo en América Latina. Santiago: Instituto de Investigación de Movimientos Sociales.

Wallerstein, I. (2001). Conocer el mundo. Saber el mundo: El fin de lo aprendido. México: Siglo XXI. 